\title{
AN ANALYSIS OF CHILDREN'S LEISURE ACTIVITY ENGAGEMENT: EXAMINING THE DAY OF WEEK, LOCATION, PHYSICAL ACTIVITY LEVEL, AND FIXITY DIMENSIONS
}

\author{
Ipek N. Sener \\ The University of Texas at Austin \\ Department of Civil, Architectural \& Environmental Engineering \\ 1 University Station, C1761, Austin, TX 78712-0278 \\ Tel: (512) 471-4535; Fax: (512) 475-8744 \\ Email: ipek@mail.utexas.edu \\ Rachel B. Copperman \\ The University of Texas at Austin \\ Dept of Civil, Architectural \& Environmental Engineering \\ 1 University Station C1761, Austin, TX 78712-0278 \\ Tel: (512) 471-4535; Fax: 512-475-8744 \\ Email: RCopperman@mail.utexas.edu \\ Ram M. Pendyala \\ Arizona State University \\ Department of Civil and Environmental Engineering \\ Room ECG252, Tempe, AZ 85287-5306 \\ Tel: (480) 727-9164; Fax: (480) 965-0557 \\ Email: ram.pendyala@asu.edu \\ Chandra R. Bhat* \\ The University of Texas at Austin \\ Dept of Civil, Architectural \& Environmental Engineering \\ 1 University Station C1761, Austin, TX 78712-0278 \\ Tel: (512) 471-4535; Fax: (512) 475-8744 \\ Email: bhat@mail.utexas.edu \\ ${ }^{*}$ corresponding author
}




\begin{abstract}
This paper presents a detailed analysis of discretionary leisure activity engagement by children. Children's leisure activity engagement is of much interest to transportation professionals from an activity-based travel demand modeling perspective, to child development professionals from a sociological perspective, and to health professionals from an active lifestyle perspective that can help prevent obesity and other medical ailments from an early age. Using data from the 2002 Child Development Supplement of the Panel Study of Income Dynamics, this paper presents a detailed analysis of children's discretionary activity engagement by day of week (weekend versus weekday), location (in-home versus out-of-home), type of activity (physically active versus passive), and nature of activity (structured versus unstructured). A mixed multiple discrete-continuous extreme value model formulation is adopted to account for the fact that children may participate in multiple activities and allocate positive time duration to each of the activities chosen. It is found that children participate at the highest rate and for the longest duration in passive unstructured leisure activities inside the home. Children in households with parents who are employed, higher income, or higher education were found to participate in structured outdoor activities at higher rates. The child activity modeling framework and methodology presented in this paper lends itself for incorporation into larger activity-based travel model systems where it is imperative that children's activity-travel patterns be explicitly modeled - both from a child health and well-being policy perspective and from a travel forecasting perspective.
\end{abstract}

Keywords: children's activity participation, leisure activities, discrete continuous models, physical activity, structured activities, unobserved factors 


\section{INTRODUCTION}

There has been an increasing interest in analyzing and modeling time use and activity-travel patterns of children. It has been found that children and students have the highest number of non-work/non-school fixed activity commitments (Frusti et al. 2003) that shape the activity-travel patterns of not only children, but also adults who must chauffer them and potentially engage in carpool arrangements with other households whose children attend the same activities (Reisner 2003). As children get older, their discretionary (but fixed) activities become more complex, resulting in greater travel constraints being placed on (often) working parents. Other household activities and trips undertaken by adults may need to be organized around the structured and fixed non-school activities undertaken by children. Therefore, a child's fixed activity commitment may make an adult unresponsive to any policy changes that attempt to modify travel mode, time of travel, or destination of travel. Thus, from a pure transportation demand analysis perspective, the ability to model children's activity engagement in structured and unstructured (non-fixed) activities, both in-home and out-of-home, would offer a strong basis to incorporate these aspects of travel demand into future activity-based travel models.

However, it is not only transportation professionals who are interested in examining children's activity engagement patterns. Child development experts note that participation in structured leisure activities helps reduce anti-social behavior, raise test scores and grades, and boost self-esteem by structuring youth's time and providing opportunities to interact with competent adults and role models (Mahoney and Stattin 2000; Carnegie Corporation of New York 1992; Huebner and Mancini 2003; Darling 2005). On the other hand, participation in unsupervised and unstructured leisure activities has been found to be correlated with higher levels of anti-social behavior and poorer educational performance (Mahoney and Stattin 2000; Osgood et al. 1996; Posner and Vandell 1994). Sociologists are concerned that children's unstructured free time is increasingly spent watching television (Hofferth and Jankuniene 2001; Copperman and Bhat 2007b) rather than in beneficial physically and mentally active free play. Although there is some evidence of the benefits of unstructured free play (Cole-Hamilton et al. 2002), watching television is generally associated with lower cognitive test scores (Timmer et al. 1985) and less time spent in reading and studying (Koolstra and van der Voort 1996). Thus, child development professionals are interested in understanding the factors that would promote healthy out-of-home extra-curricular activity participation and time use, and discourage passive television viewing.

Finally, public health professionals are interested in understanding children's activity engagement patterns, specifically their level and type of physical activity participation, due to 
concerns surrounding rising childhood obesity, cardiovascular diseases, and diabetes. Several studies have found a strong positive correlation between physically active lifestyles and development of strong, healthy, and intelligent children (Transportation Research Board and Institute of Medicine 2005; USDHHS 2000). At the same time, the Centers for Disease Control (CDC 2003) reports that more than $60 \%$ of children aged 9-13 years do not participate in any organized physical activity during their non-school hours and more than $20 \%$ do not engage in any free-time physical activity. Only $36 \%$ of students meet recommended levels of physical activity (CDC 2006). About one-third of teenagers do not engage in adequate physical activity for health (CDC 2002). In this context, transportation and public health professionals are interested in understanding the relative impacts of socio-economic, demographic, and builtenvironment attributes on physical activity participation, particularly in children (see Sallis et al. 2000 , for a review of studies examining factors affecting physical activity levels).

The above discussion clearly motivates research into the nature of discretionary activity engagement by children. In this paper, data from the 2002 Child Development Supplement (CDS) of the Panel Study of Income Dynamics (PSID) is used to model children's leisure activity engagement by day of week (weekday versus weekend), location (in-home versus out-of-home), type (physically active versus passive), and nature (structured/organized versus unstructured). The data offer detailed information about leisure activities undertaken by children on one weekday and one weekend day. As children can engage in multiple discretionary activities within the same day and allocate time to each of the activities, a mixed multiple discretecontinuous extreme value (MDCEV) model formulation is adopted. The model sheds considerable light on the observed socio-economic and demographic variables and unobserved factors that influence children's leisure activity engagement.

Following a brief review of the literature on children's activity engagement patterns, this paper describes the data set and sample used in this study. The sample description is followed by a presentation of the modeling methodology. Model estimation results are presented in the fifth section and conclusions are summarized in the final section.

\section{ACTIVITY ENGAGEMENT PATTERNS OF CHILDREN}

In this section, a few highlights from the literature regarding the activity engagement patterns of children are documented. Within the scope of this paper, it is impossible to provide a comprehensive multi-disciplinary literature review on this topic. The intent of the discussion here is to demonstrate the level of interest in this topic and the types of analyses that have been conducted in the past. 
Several studies have examined out-of-school activity participation rates for children. For example, Huebner and Mancini (2003) analyzed activity patterns of 509 students in grades 9-12 and found that $26 \%$ of those observed do not participate in any extra-curricular activities after school and $75 \%$ spent no time in non-school clubs. Hofferth et al. (1991) focused on activity patterns of younger children 5-12 years old and found participation rates to be more dismal with only $12 \%$ of $5-9$ year olds and $23 \%$ of $10-12$ year olds participating in after-school enrichment activities. Posner and Vandell (1997) examined activity patterns of 194 black and white children in grades 3-5 and noted that $20 \%$ of after-school time was spent watching television, but only $4 \%$ was spent in coached sports. Shann (2001) measured activity participation rates for 1583 inner-city middle schoolers and found that more than $75 \%$ of children did not participate in any after-school programs. On the other hand, nearly $90 \%$ watched television in a passive mode. Participation in structured extra-curricular activities is substantially higher in Sweden with more than $75 \%$ of boys and girls reporting involvement in such activities (Mahoney and Stattin 2000).

These studies have also noted that there are socio-economic and demographic factors that influence children's engagement in extra-curricular activities. Parent involvement and endorsement, socio-economic status and education level of parents, and being in a household with married parents positively contributed to participation in extra-curricular activities (Huebner and Mancini 2003). Gender differences have also surfaced in these studies with boys generally participating in more structured sports activities than girls who tended to participate in more unstructured socialization and academic activities. Individuals who participated in extracurricular activities on weekdays were also found to participate in such activities at higher rates on weekends. Darling (2005), in examining the activity patterns of 3761 high-schoolers, found that White students participated in organized activities at higher rates than Hispanics, who showed the lowest level of participation among all groups. Participation in organized activities was found to be positively correlated with academic performance and desirable behaviors.

Virtually all of the studies discussed above simply examined participation rates and paid little to no attention to the duration or amount of time devoted to the activities. In this context, recent studies by Copperman and Bhat (2007a, 2007b) and Sener and Bhat (2007) are noteworthy. Copperman and Bhat (2007a) examined out-of-home weekend time use patterns of children aged 5-17 years and find that only $32 \%$ of children participate in some form of physical activity during the weekend day. Copperman and Bhat (2007b) analyzed children's time use with a focus on in-home versus out-of-home activity engagement patterns. On average, children undertake recreational activities for 3.5 hours on weekdays and 6 hours on weekend days with the highest participation rate in and time allocated to watching television. 
On weekdays, $85 \%$ watch television and spend an average of two hours doing so; on weekend days, the corresponding values are $90 \%$ and three hours. Recreation is primarily in-home; $89 \%$ of weekday recreation and $80 \%$ of weekend recreation is done at home. Sener and Bhat (2007) examined out-of-home weekend time use patterns of 1574 children aged 5-15 years with an emphasis on accompanying individuals and highlight the important role of social networks and parental roles in children's activity engagement. Mackett et al. (2005) reported a study of 200 children aged 10-13 years who were fitted with three-dimensional motion sensors and asked to fill out travel and activity diaries over a period of four days. They note that walking, by itself, serves as a physical activity. They also find that unstructured activities are more physically intensive than structured activities and that time spent in-home is less intensive than time spent outside home.

This section highlights the multidisciplinary interest in analyzing children's leisure activity engagement patterns by nature, type, and day of week. There are numerous other studies devoted to school mode choice of children and levels of involvement in physically active recreational episodes and lifestyles (see, for example, Clifton 2003; McMillan 2007; McDonald 2006; and Krizek et al. 2004). Overall, it can be seen that there is much interest in the extracurricular activity engagement patterns of children and this study is aimed at making a substantive contribution to understanding the observed and unobserved factors that influence children's participation in and time allocation to such activities.

\section{DATA SOURCE AND SAMPLE FORMATION}

\subsection{Data Source}

The data for this study is derived from the 2002 Child Development Supplement (CDS) to the Panel Study of Income Dynamics (PSID). The PSID is a longitudinal study that has collected, since 1968, demographic, employment, and health information from a nationally representative sample of individuals and households. The CDS involved collecting data on over 2,500 children through health and achievement test surveys, primary caregiver and child interviews, and a twoday time-use diary - one for a weekday and the other for a weekend day. The time use diary collected detailed information on the type, number, duration, and location of activities for each 24-hour survey day beginning at midnight. The diary also collected information on who was present during the activity, and among those present, who actually participated in the activity. The diary includes information for both in-home and out-of-home activities and employs a detailed activity classification scheme and location typology to capture the spatial dimension of activity episode participation. Paper diaries were mailed to children, filled out on or around the 
activity day, and then retrieved and reviewed by an interviewer either by phone or in person. Older children and adolescents were expected to fill out their own diary, while primary caregivers aided younger children.

\subsection{Sample Description}

\subsubsection{Definitions of Activity Types and Categories}

Before discussing the process followed in sample formation for the current analysis, it is useful to clarify the activity classification scheme and definitions adopted in this paper. Activities are characterized by four distinct dimensions with two categories in each dimension. This leads to a total of $2^{4}$ or 16 categories of activities. The dimensions and categories are as follows:

\section{Dimension 1: Type of Activity}

An activity may be either "physically active (PHY)" or "physically passive (non-PHY)". A physically active episode requires regular bodily movement to accomplish the activity while a passive episode involves maintaining a sedentary and stable position for the duration of the activity. Playing a sport is a physically active episode while watching television is a physically passive episode.

\section{Dimension 2: Nature of Activity}

An activity may be either "structured (STR)" or "unstructured (non-STR)". A structured activity is an organized activity that is usually characterized by regular time schedules, specified locations, and adult supervision. An unstructured activity is one which has no set schedule or regimen and does not involve organized adult supervision.

Dimension 3: Day-of-week of Activity

An activity may occur either on a "weekday (WD)" or a "weekend (WE)" day.

\section{Dimension 4: Location of Activity}

An activity may occur either "in-home (IH)" or "out-of-home $(\mathrm{OH})$ ".

All possible combinations of the above yield a total of 16 activity categories. However, it was found that there were virtually no "structured in-home activities" in the data set used in this study. This eliminated four categories from the possible 16, yielding a final set of 12 possible activity categories for analysis, with children having the ability to participate in more than one activity category on any given day. The final 12 activity categories are:

- Weekend Passive Unstructured Activity - $\mathrm{IH}$ and $\mathrm{OH}$

- Weekday Passive Unstructured Activity - $\mathrm{IH}$ and $\mathrm{OH}$

- Weekend Physically Active Unstructured Activity - IH and OH

- Weekday Physically Active Unstructured Activity - $\mathrm{IH}$ and $\mathrm{OH}$ 
- Weekend Passive Structured Activity - OH only

- Weekday Passive Structured Activity - $\mathrm{OH}$ only

- Weekend Physically Active Structured Activity - $\mathrm{OH}$ only

- Weekday Physically Active Structured Activity - OH only

\subsubsection{Sample Formation}

The final sample used for analysis in this paper includes 1810 children aged 5-15 years of age ${ }^{1}$. Only children who filled both weekday and weekend day activity diaries were included in the final sample for analysis. All activity episodes were categorized by purpose and only leisure activity episodes were extracted for this study. Based on the definitions presented earlier, all activities were classified as either structured or unstructured and physically active or passive, thus completing the definition of the activities for purposes of the analysis presented in this paper. The time investments across all episodes in the day within each of the 12 activity categories were aggregated to obtain total daily time investments in each of the categories. Thus, for each individual, there is a complete profile of multiple activity participation and daily time allocation, both for weekdays and weekend days. Individual and household demographic and socio-economic characteristics were appended to the activity and time use data set to compile a comprehensive database suitable for modeling children's activity engagement patterns as a function of observed characteristics.

\section{DESCRIPTIVE TIME-USE STATISTICS}

Before examining activity participation rates and time use allocation behavior of children, it is useful to review the socio-economic and demographic profile of the sample of 1810 children used in the analysis. In the sample, $923(51 \%)$ are male, 901 (50\%) are Caucasian American, $669(37 \%)$ are African American, and $129(7 \%)$ are Hispanic. The age distribution shows that $494(27 \%)$ are 5-7 years, $695(38 \%)$ are 8-11 years, and $621(34 \%)$ are $12-15$ years. In terms of parental demographics, it was found that $613(34 \%)$ children have an employed father while 617 (34\%) have an employed mother. Finally, 459 (25\%) children are from low income (earning less than 25,000 US dollars per year) households. Overall, the demographic profile of the sample

\footnotetext{
${ }^{1}$ The reader will note that we adopt the "child-centric" approach in the current paper. That is, in analyzing children's activity-travel patterns, children are chosen as the units of analysis and treated as decision makers. This approach recognizes that children as young as 6-8 years start developing their own identities, taste preferences, and social needs (see Stefan and Hunt, 2006, CDC, 2005, Eccles, 1999). They then interact with their parents and other adults to facilitate these needs.
} 
suggested that there is sufficient variation, but no strong biases, in the sample appropriate for model estimation.

Each child in the survey completes a time use diary of leisure activities for one weekday and one weekend day. In the sample, 921 children provided time use diaries for Saturday, while 889 provided diaries for Sunday. The distribution of the sample across the weekdays is quite uniform with 368 children providing time-use diaries on Monday, 380 on Tuesday, 335 on Wednesday, 353 on Thursday, and 374 on Friday. Also, the combination of weekdays and weekend days is fairly evenly distributed across the sample. For instance, of the 374 children who reported leisure activities for Friday, 180 children reported their leisure activities for Saturday, while 194 did so for Sunday.

Table 1 shows aggregate participation rates in leisure activities for the sample of 1810 children. About $92 \%$ of children participated in at least one out of home leisure activity over the course of the two day types (weekday and weekend day). As expected, more children participate in out-of-home leisure activities on weekend days only compared to weekdays only, presumably because there is more discretionary time available on weekends when there is no school. This finding is also supported by Stefan and Hunt (2006) and Copperman and Bhat (2007b). Only $51 \%$ of children reported doing out-of-home leisure activities on both weekdays and weekend days. About $63 \%$ of children reported pursuing some form of physically active leisure activity over the course of the two day types (weekday and weekend day). Participation rates are about the same (at 39\%) for in-home and out-of-home physically active leisure activities, but only about $16 \%$ of children report undertaking both in-home and out-of-home physically active leisure activities. This finding suggests that it is important to look at both inhome and out-of-home physical activity participation to get a complete picture of physical activity participation by children. Weekday and weekend day physical activity participation rates were also similar, with slightly higher rates on the weekend. Only $10 \%$ of children participate in out-of-home physically active leisure episodes on both days. With respect to structured activity participation, $43 \%$ of children engage in some sort of structured leisure activity (by definition, this activity is out-of-home in the context of this paper). Similar results are shown by Huebner and Mancini (2003). The rate is higher on weekends. Only $10 \%$ of children report undertaking any structured activity on both weekdays and weekend days.

\section{[INSERT TABLE 1 HERE]}

Table 2 provides detailed statistics on activity participation rates (column 3 ) and average time investments conditional on participation (column 4) in leisure activities of all types. All children participate in in-home, unstructured, passive activities (e.g., watching television) on 
both weekdays and weekend days. These two activity categories therefore show 100\% participation and are considered "consumed" by all individuals (children) in the sample. The question then is, what additional activity categories are "consumed" and for how long? The largest participation rate and duration for out-of-home activities is in the weekend (WE), nonphysical (non-PHY), unstructured (non-STR) activity types (alternative 5). The lowest participation rates are observed in the weekend (WE) and weekday (WD), out-of-home (OH), physically active (PHY), structured (STR) activity types (alternative 11 and 12 in Table 2). But conditional upon participation, these are among the activity types with highest duration of participation (suggesting that there is a low baseline preference and low satiation levels for these activity types; more on this in subsequent sections of the paper). Most children indulge in at least three different activity type combinations over the two day period as evidenced by the finding that $96 \%$ of children participate in the two passive in-home activity types and at least one other activity type on both weekdays and weekend days (see the last column of the first two numerical rows of Table 2). It is to be noted that the solo and multiple activity participation rates (last two columns of the table) are computed for alternatives 3 through 12 in the table without considering the two in-home, unstructured, passive activity categories that are always consumed. Thus, for instance, the values for the WE/IH/PHY/non-STR activity type (alternative 3 ) indicate that 38 of the 521 (7\%) children participate only in this activity (besides the in-home, unstructured, passive activities that are pursued by everybody). On the other hand, 483 (i.e., 93\%) children participate in at least one additional activity type besides WE/IH/PHY/non-STR (and the in-home, unstructured, passive activities consumed by everybody). Overall, the high prevalence of participation in multiple discretionary activity types, as evidenced by the last column of the table, highlights the need for and appropriateness of adopting MDCEV modeling methodology to represent children's leisure activity engagement and time allocation.

[INSERT TABLE 2 HERE]

\section{THE MULTIPLE DISCRETE CONTINUOUS EXTREME VALUE (MDCEV) MODEL}

This section presents an overview of the MDCEV model structure, including a discussion of the basic structure of the model followed by a description of the mixed MDCEV model structure. These models are used to examine children's daily participation, and time investment, in each discretionary activity type (purpose) over the course of the two day observation period (i.e. across the weekend day and the weekday). The MDCEV model is ideally applicable to the current application of time-use modeling since it is based on the concept that children participate in multiple discretionary activity types due to diminishing marginal returns from 
participation in any single activity type. ${ }^{2}$ The reader is referred to Bhat (2005) and Bhat (2008) for more extensive descriptions of the intricate details of the model structure, rationale, and methodology.

\subsection{Basic Structure}

Without loss of generality, designate the first two alternatives ( $k=1$ and $k=2$ ) as the in-home, passive, unstructured leisure activities pursued during the weekday and weekend day, respectively. Since all children participate for some amount of time in these two activity categories, these two alternatives constitute the "outside good" in the MDCEV model ${ }^{3}$. The remaining (K-2) alternatives correspond to each different type of leisure activities categorized based on the activity day (weekday or weekend), activity location (in-home or out-of home), activity type (physically active or passive), and activity nature (structured or unstructured), for a total of 14 alternatives. Let $t_{k}$ be the time invested in alternative $k(k=1,2, \ldots, K ; K=14)$, and consider the following additive utility function form ${ }^{4}$ :

$$
U(\boldsymbol{t})=\exp \left(\varepsilon_{1}\right) \ln \left(t_{1}\right)+\exp \left(\beta^{\prime} z_{2}+\varepsilon_{2}\right) \ln \left(t_{2}\right)+\sum_{k=3}^{K} \gamma_{k} \exp \left(\beta^{\prime} z_{k}+\varepsilon_{k}\right) \ln \left(\frac{t_{k}}{\gamma_{k}}+1\right)
$$

In the above expression, the individual has the vector $t$ as the decision vector. The first two elements of $\boldsymbol{t}$ should be positive since they constitute the outside alternatives, while the third through $K^{\text {th }}$ elements of $\boldsymbol{t}$ can either be zero or some positive value. In this respect, whether or not a specific $t_{k}$ value $(k=3,4, \ldots, K)$ is zero constitutes the discrete choice component, while the magnitude of each non-zero $t_{k}$ value $(k=1,2, \ldots, K)$ constitutes the continuous choice component. $z_{k}$ in Equation (1) is a vector of exogenous determinants (including a constant) specific to alternative $k$ (there is no such vector for the first alternative because only differences in utilities matter, as shown later). The term $\exp \left(\beta^{\prime} z_{k}+\varepsilon_{k}\right)$ represents the random marginal utility of one unit of time investment in alternative $k$ at the point of zero time investment for the

\footnotetext{
${ }^{2}$ MDCEV is a theoretically appealing, conceptually intuitive, and relatively simple structure for time allocation analysis. This is not a standard RUM-based discrete choice model like the multinomial logit or nested logit. In these standard models, only one alternative can be chosen and there is no continuous element. On the other hand, in the RUMbased MDCEV model, multiple alternatives can be chosen for consumption, and there is a continuous component of consumption.

${ }^{3}$ The term "outside good" refers to a good that is "outside" the purview of the choice of whether to be consumed or not. That is, the "outside good" is a good that is always consumed by all consumers. Within this modeling framework, the in-home, unstructured, passive activities that are pursued by all children on weekdays and weekend days are considered "outside" alternatives, while all other activities (where participation rates are less than 100\%) are referred to as "inside" alternatives.

${ }^{4}$ Several other utility function forms were also considered, but the one presented provided the best data fit in the empirical analysis of the current paper. For conciseness, these alternative forms are not discussed. The reader is referred to Bhat (2008) for a detailed discussion of alternative utility forms.
} 
alternative. This can be observed by computing the partial derivative of the utility function $U(t)$ with respect to $t_{k}$ and computing this marginal utility at $t_{k}=0$ (i.e., $\partial U(\mathbf{t}) /\left.\partial t_{k}\right|_{t_{k}=0}$ ). Thus, $\exp \left(\beta^{\prime} z_{k}+\varepsilon_{k}\right)$ controls the discrete choice participation decision in alternative $k$ (although the functional form in Equation (1) ensures participation in the first two alternatives). We will refer to this term as the baseline preference for alternative $k$. The term $\gamma_{k}$ is a translation parameter that serves to allow corner solutions for the "inside" alternatives $k=3,4, \ldots, K\left(\gamma_{k}>0\right)$. That is, these $\gamma_{k}$ terms allow for the possibility that the individual invests no time in alternatives $k=3$, $4, \ldots, K$. In addition to serving as translation parameters, the $\gamma_{k}(k=3,4, \ldots, K)$ terms also serve as the satiation parameters for these inside alternatives - values of $\gamma_{k}$ closer to zero imply higher satiation (or lower time investment) for a given level of baseline preference (see Bhat 2008) ${ }^{5}$. There are no $\gamma_{k}$ terms for the first two alternatives (i.e., for $k=1$ and $k=2$ ) because they are always consumed. The constraint that $\gamma_{k}>0$ for $k=3,4, \ldots, K$ is maintained by reparameterizing $\gamma_{k}$ as $\exp \left(\lambda_{k}{ }^{\prime} \omega_{k}\right)$, where $\omega_{k}$ is a vector of child-related characteristics and $\lambda_{k}$ is a vector to be estimated.

From the analyst's perspective, individuals are maximizing random utility $U(t)$ subject to the time budget constraint that $\sum_{k} t_{k}=T$, where $T$ is the total time available for children to participate in discretionary activity pursuits. The optimal time investments $t_{k}^{\star}(k=1,2, \ldots, K)$ can be found by forming the Lagrangian function (corresponding to the problem of maximizing random utility $U(t)$ under the time budget constraint $T$ ) and applying the Kuhn-Tucker (KT) conditions. After extensive, but straightforward, algebraic manipulations, the KT conditions collapse to (see Bhat, 2008):

$$
\begin{aligned}
& V_{k}+\varepsilon_{k}=V_{1}+\varepsilon_{1} \text { if } t_{k}^{*}>0(k=2,3, \ldots, K) \\
& V_{k}+\varepsilon_{k}<V_{1}+\varepsilon_{1} \text { if } t_{k}^{*}=0(k=3,4, \ldots, K), \text { where } \\
& V_{1}=-\ln \left(t_{1}^{*}\right), \\
& V_{2}=\beta^{\prime} z_{2}-\ln \left(t_{2}^{*}\right), \text { and }
\end{aligned}
$$

\footnotetext{
${ }^{5}$ In the context of this paper, satiation effects are defined as the diminishing marginal returns from the invested time in a discretionary activity category as the time invested in that activity category increases. Satiation effects are based on the aggregate time consumption in a particular activity on the designated day. That is, satiation effects are incorporated at the day-level rather than at the individual episode-level.
} 


$$
V_{k}=\beta^{\prime} z_{k}-\ln \left(\frac{t_{k}^{*}}{\gamma_{k}}+1\right)(k=3,4, \ldots, K)
$$

Assuming that the error terms $\varepsilon_{k}(k=1,2, \ldots, K)$ are independent and identically distributed across alternatives with a type 1 extreme value distribution, the probability that the child allocates time to the first $M$ of the $K$ alternatives (for duration $t_{1}^{*}$ in the first alternative, $t_{2}^{*}$ in the second, $\ldots t_{M}^{*}$ in the $M^{\text {th }}$ alternative) is (see Bhat, 2008):

$$
\begin{aligned}
& P\left(t_{1}^{*}, t_{2}^{*}, t_{3}^{*}, \ldots t_{M}^{*}, 0,0,0 . .0\right)=\left[\prod_{i=1}^{M} c_{i}\right]\left[\sum_{i=1}^{M} \frac{1}{c_{i}}\right]\left[\frac{\prod_{i=1}^{M} e^{v_{i}}}{\sum_{k=1}^{K} e^{v_{k}}}\right](M-1) !, \text { where } \\
& c_{1}=\left(\frac{1}{t_{1}^{*}}\right), c_{2}=\left(\frac{1}{t_{2}^{*}}\right), \text { and } c_{i}=\left(\frac{1}{t_{i}^{*}+\gamma_{i}}\right) \text { for } i=3,4, \ldots, M .
\end{aligned}
$$

\subsection{Mixed MDCEV Structure and Estimation}

The structure discussed thus far does not consider correlation among the error terms in the baseline preferences of the alternatives. However, it is possible that children who like to participate in a certain kind of discretionary activity (say, a physically active activity) due to unobserved individual characteristics will participate more than their observationally-equivalent peers in all activity types involving a physically active activity. Such error components can be accommodated by defining appropriate dummy variables in the $z_{k}$ vector to capture the desired error correlations, and considering the corresponding $\beta$ coefficients in the baseline preference of the MDCEV component as draws from a multivariate normal distribution. In general notation, let the vector $\beta$ be drawn from $\phi(\beta)$. Then the probability of the observed time investment $\left(t_{1}^{*}\right.$, $\left.t_{2}^{*}, \ldots t_{M}^{*}, 0,0, \ldots 0\right)$ for the child can be written as:

$$
P\left(t_{1}^{*}, t_{2}^{*}, \ldots t_{M}^{*}, 0,0,0 . .0\right)=\int_{\beta} P\left(t_{1}^{*}, t_{2}^{*}, . . t_{M}^{*}, 0,0, . .0 \beta\right) \phi(\beta) d \beta
$$

where $P\left(t_{1}^{*}, t_{2}^{*}, \ldots, t_{M}^{*}, 0,0, \ldots 0 \mid \beta\right)$ has the same form as in Equation (3).

The parameters to be estimated in Equation (4) include the $\beta$ vector, the $\lambda_{k}$ vector embedded in the $\gamma_{k}$ scalar $(k=3,4, \ldots, K)$, and the $\sigma$ vector characterizing the covariance matrix of the error components embedded in the $\beta$ vector. The likelihood function (4) includes a multivariate integral whose dimensionality is determined by the number of error components 
in $\beta$. The parameters can be estimated using a maximum simulated likelihood approach. Halton draws are used in the current research for estimation (see Bhat, 2003). The sensitivity of parameter estimates was tested with different numbers of Halton draws per observation for the specifications considered in this paper, and the results were found to be very stable with as few as 100 draws per observation. In this analysis, 125 Halton draws per observation were used in the estimation.

\section{MODEL ESTIMATION RESULTS}

A series of mixed MDCEV model specifications were developed and estimated for this study. Several different variable specifications and functional forms (e.g., linear and non-linear income and age effects) and error component specifications were attempted to identify the model specification that provided the most intuitively appealing behavioral interpretation and statistical indications ${ }^{6}$. The final set of exogenous variables includes child demographics, parent demographics, household demographics, household location variables, and activity day variables.

Model estimation results are presented in Table 3 and discussed in this section. It should be noted that, where dummy variable representation is used, the omitted category or categories serve as the baseline reference.

\section{[INSERT TABLE 3 HERE]}

\subsection{Child Demographics}

As expected, the characteristics of the child influence leisure activity participation patterns. Relative to older children aged 12-15 years, those aged 5-11 years are generally less likely to engage in leisure activities on weekdays, out-of-home, and unstructured. These findings are consistent with the notion that younger children are not likely to have the same level of weekday structured out-of-home activity opportunities as older children, and even if they do, parents may not be as comfortable sending them to such activities in comparison to older and more mature children. These effects are seen further in the lower propensity for young children aged 5-7 years to pursue weekday, out-of-home, structured, and weekend, out-of-home, physically active, unstructured activities (see the negative coefficients on the interaction terms in the column corresponding to children aged 5-7 years in Table 3). On the other hand, younger children are engaging in more physically active leisure activities suggesting that children may become more sedentary (particularly when in-home) as they age. Male children are less likely to pursue

\footnotetext{
${ }^{6}$ It should be noted that a few statistically insignificant variables were retained in the final models as they were considered important to understand the relative impacts of explanatory factors on children's leisure activity patterns.
} 
leisure activities out-of-home, particularly those that are passive and structured on weekdays (arts and crafts, music lessons), but are more likely to engage in physically active episodes. Caucasian American children are more likely to engage in physically active recreational activities and weekday, out-of-home, structured activities (whether passive or physically active). Hispanic children are more likely to pursue out-of-home and physically active recreational activities suggesting that these children get together outside home to play informally (as opposed to participation in structured activities). Finally, consistent with the expectations that such children have greater constraints than others, physically challenged children are found to participate less in physically active and out-of-home activities.

The results indicate that older children (aged 12-15) are more likely to participate in outof-home structured activities, but less likely to participate in physical activities than younger children. These findings suggest that promoting opportunities for participation in structured physical activities in early childhood may increase physical activity participation throughout childhood. In addition, it is essential to encourage children to remain in these physically active programs as they move into adolescence. The results also support the notion that Caucasian Americans are participating to a greater degree in structured activities compared to their ethnic minority counterparts. It may be necessary to enhance the opportunities for structured activities available to minority youth so as to promote and encourage participation in both physically active and passive structured activities.

\subsection{Parent Demographics}

With respect to the impact of parent demographics, the level of participation in out-of-home and structured leisure activities is higher in households where the parents are employed and/or have higher education levels. It is likely that these parents encourage their children to participate in such activities, have the need for children to do so because they are unable to supervise them after school due to work schedule constraints, and/or have the disposable income required to afford sending their children to such activities. Children are also found to follow after their parents; if the parents are physically active (whether structured or unstructured, in-home or outof-home), then the children are likely to be active as well.

The findings point to the need to promote awareness and structured activity opportunities in areas where the parents may be less educated, lower income, or unemployed. The finding that children are less likely to be physically active if their parent's are not physically active suggests that family oriented programs focused on encouraging physical activity among 
all members of the family may be successful in increasing physical activity levels among children.

\subsection{Household Demographics}

Household demographics play an important role in determining the nature of children's leisure activity participation and time investment. Being in a household with more children or low income (less than $\$ 25,000$ per year) tends to decrease child activity levels out-of-home. This is presumably due to the additional constraints placed on the household by these attributes. As mentioned earlier, these findings suggest the need for enhancing opportunities available to these demographics groups. In addition, it is necessary to ensure that these activities are accessible from a transportation perspective as these households are likely to be modeconstrained as well. Another interesting result of the study indicates that as the number of children increases in a household, they are more likely to engage in physically active and structured activities. This is possibly due to the ability to play with each other and economies of scale in placing them in structured activities. Kids of single parents are likely to participate at greater levels in out-of-home activities, presumably because children of single parents indulge in activities outside home when the single parent is busy working or taking care of household obligations. As the number of vehicles in the household increases, children are less likely to indulge in physically active episodes, presumably due to built-environment attributes in higher car ownership neighborhoods (suburban low-density) that are not conducive to participation in physically active pursuits. What lends credence to this hypothesis is the finding that those living in apartments (as opposed to single-family dwelling units) are more likely to participate in out-ofhome activities, presumably because of the greater community feel and higher density living associated with apartments (see Bhat and Gossen 2004 for a similar result).

\subsection{Household Location Variables and Seasonal Effects}

With respect to household location variables and seasonal effects, it is found that children living in rural areas are less likely to participate in out-of-home activities, but more likely to participate in physically active and structured activities. It is not readily apparent why rural areas influence children's activity participation in this way and these findings merit further investigation. Those living in colder northeast and north-central states are less likely to participate in out-of-home and physically active episodes, presumably due to weather-related limitations. Indeed, this is borne out further with the finding that out-of-home and structured activity participation decreases in the winter, presumably because many outdoor structured activities shut down during the winter 
months. Out-of-home physical activities are also pursued less in the Fall. These findings are consistent with those obtained by Sener and Bhat (2007) and also reported by Ross (1985) who noted that physical activity is highest in summer, drops in fall, reaches a low point in winter, and increases again in spring. It may be prudent for policymakers to consider enhancing indoor structured activity opportunities during the cold winter months.

\subsection{Baseline Preference Constants}

The final section of Table 3 presents the baseline preference constants for the various activity categories. The base alternative is the weekend, in-home, passive, unstructured activity category (e.g., watching TV or playing on the computer at home on weekends). Compared to this base alternative, all other activity categories without exception have negative baseline preference constants suggesting that, relative to the base alternative, participation in all other leisure activities is lower (for the second alternative, the negative sign in Table 3 reflects the lower preference in terms of the duration of time investments compared to the first alternative; the first and second alternatives are chosen by all children). The lowest baseline preference constants are seen for weekend and weekday out-of-home, physically active, structured activities. This suggests that children are least likely to indulge in these types of leisure activities, which does not bode well for those concerned with the healthy social and physical development of children.

\subsection{Satiation Parameters}

Satiation parameter estimates are presented in Table 4 for all activity categories. The satiation parameter values are significantly different from 0 , thereby indicating that there are clear satiation effects in discretionary activity time investments. Specifically, the higher the value of $\gamma_{k}$, the less is the satiation effect in the consumption of the alternative $k$ (Bhat 2008). The satiation parameter $\gamma_{k}(k=3,4, \ldots, K)$ for the inside alternatives (i.e., the 10 discretionary activity alternatives) influence the length of participation in any alternative. There are no $\gamma_{k}$ terms for the first two alternatives (i.e., for $k=1$ and $k=2$ ) because they are always consumed. It is found that the satiation effect is largest for the fourth alternative of weekday, in-home, physically active, unstructured activity type (such as playing in the backyard after school on a weekday). This is consistent with the finding that these activities have the lowest average duration. In general, it is found that the structured activity types have lower satiation levels than unstructured activity types, presumably because children can easily quit engaging in 
unstructured activities while they must adhere to the activity schedule for organized activities. Further, it is found that time spent in physically active structured activities is greater than that in unstructured physically active activities suggesting that children need structure and supervision to engage in physically active pursuits for longer periods of time. It is also found that activity types on weekdays have higher satiation levels (notice the relatively lower value of $\gamma_{k}$ for the weekday activities) than activities on weekends, presumably because children have more free time to indulge in these types of activities.

\section{[INSERT TABLE 4 HERE]}

\subsection{Error Components}

The final model specification included three error components which are specific to:

- Activity Location - Out-of-home

- Type of Activity - Physically active

- Nature of Activity - Structured

The error component for out-of-home activities has a standard deviation of 0.65 with a t-statistic of 15.80 , indicating significant individual specific unobserved factors that predispose children to out-of-home activity engagement. For instance, a child predisposed to out-of-home leisure activities has a higher baseline preference than his/her observationally-equivalent peers in all activity types that are out-of-home (regardless of activity day and type). The error component for physically active episodes has a standard deviation of 0.53 with a t-statistic of 9.18 , indicating individual specific unobserved factors that predispose children to physically active activities. Finally, the error component for structured activities has a standard deviation of 0.76 with a t-statistic of 9.63 , indicating individual specific unobserved factors that predispose children to participate in structured activities. These findings are consistent with expectations. For example, a child who likes to be physically active is likely to prefer these types of activities regardless of location, day, and fixity. Similarly, families and their children that prefer structured activities are likely to do so regardless of day of week, location, and physical level of activity.

\subsection{Likelihood-Based Measures of Fit}

The log-likelihood value at convergence of the final model is -17410 while the corresponding value for the model without mixing (accounting for taste variations) is 17499 . Further, the likelihood value for the model with only the MDCEV baseline preference constants and the satiation parameters is $\mathbf{- 1 7 7 4 5}$. The likelihood ratio test for testing the presence of exogenous variable effects and unobserved heterogeneity is 670 , which is substantially larger than the critical $X^{2}$ value with 50 degrees of freedom at any level of significance. In addition, the 
likelihood test for testing the presence of taste variations is 178 , which is also considerably larger than the critical $x^{2}$ value with 3 degrees of freedom. These results indicate the appropriateness of using the mixed version of the MDCEV model for modeling child leisure activity engagement.

\section{CONCLUSIONS}

There is considerable interest among professionals in several disciplines in leisure activity engagement patterns exhibited by children. Child development professionals are interested in the sociological aspects of child leisure activity engagement and health professionals are interested in the physically active nature of children's discretionary activity participation. In the transportation planning context, travel demand modelers are interested in children's activitytravel patterns because they impact travel patterns of adults which, in turn, has important implications for activity-travel model specification. Transportation professionals are increasingly seeing themselves drawn into the debate as to whether the built environment, including the land use-transport system configuration, is affecting children's activity-travel behavior and therefore health. Despite this widespread interest, there is limited research examining and modeling children's activity-travel engagement in a rigorous econometric framework.

In this paper, data from the 2002 Child Development Supplement (CDS) of the Panel Study of Income Dynamics (PSID) is used to study children's leisure activity participation along multiple dimensions including day of week (weekday versus weekend day), location of activity (in-home versus out-of-home), type of activity (physically active versus passive), and nature of activity (structured or organized versus unstructured or spontaneous). A total of 12 activity categories are considered in the analysis and a final sample of more than 1800 children aged 515 years is analyzed. A mixed multiple discrete-continuous extreme value (MDCEV) modeling approach is adopted to account for the fact that children may indulge in multiple activities, allocate time investments to multiple activities, and unobserved factors may influence discretionary activity participation by predisposing children to prefer certain types of activities based on their inherent lifestyle preferences and attitudes.

The data analysis and model estimation results offer intuitively appealing and behaviorally plausible interpretations. In general, all children were found to participate in athome, unstructured, passive activities both on weekdays and weekend days. In fact, these activities also accounted for the largest time investments as well. These include such passive in-home activities as watching television, playing video and computer games, or talking inperson or via telecommunications technologies. Children were less participatory in out-of-home, 
physically active, structured activities which does not bode well from a sociological and public health perspective. A host of socio-economic and demographic characteristics including age, gender, race, parents education and employment status, income, housing unit type, vehicle ownership, and household composition (family structure, number of children) significantly influence children's leisure activity engagement.

From a travel demand modeling standpoint, one of the weaknesses of emerging activitybased travel demand model systems is the lack of richness in the representation of the activity patterns of children. Not only does this result in the absence of much needed policy information for promoting active lifestyles among youth, but it also results in an inadequate representation of the activity-travel patterns of children. The models presented in this paper offer a rich framework for categorizing and representing the activity-travel patterns of children in larger travel demand model systems. The paper provides a taxonomy of child activities that explicitly considers the spatial and temporal constraints that may be associated with different types of activities (e.g., structured versus unstructured). The modeling methodology in the paper is capable of accounting for multiple activity participation, satiation effects, time allocation, and taste variations (unobserved factors affecting leisure activity engagement). By incorporating models such as that presented in this paper into travel demand model systems, one can forecast household travel behavior in a more comprehensive framework that explicitly considers constraints and opportunities (not only for adults, but for children as well) and interactions (between adults and children).

Unfortunately, built environment attributes (including land use and transport system design variables) were not readily available in the data set to be able to identify transport and land use systems configurations and policies that professionals can adopt to promote healthy lifestyles among children. Future research efforts should attempt to include a larger set of such variables so that the model is more policy sensitive from a transport and land use perspective. Nevertheless, the model offers valuable insights into children's leisure activity participation propensities and the observed and unobserved factors that influence these patterns. The use of a mixed model specification allows the identification of activity types whose participation may be influenced by unobserved components. In this particular context, lifestyle preferences and values (unobserved factors) were found to impact participation in out-of-home, physically active, and structured activities. The use of satiation parameters in the model specification allows the determination of the relative satiation effects among activity categories. Low satiation effects are found for structured activities while high satiation effects are found for unstructured, physically active, in-home activities - particularly on weekdays. The model diagnostics clearly 
indicate the appropriateness of and the need for adopting a model formulation such as that used in this paper.

In addition to considering a richer set of transport and land use descriptor variables, the research can be further enhanced by integrating travel choices together with activity participation choices to form an integrated model of activity engagement and travel choices (conditional on activities being pursued outside home). By integrating travel choices into the model system, one can get a more complete picture of physically active and passive activity engagement patterns of children. Also, future research should focus on explicitly modeling interactions between children's and adults activity-travel patterns and devising ways of integrating such interactions in comprehensive activity-based microsimulation model systems.

\section{ACKNOWLEDGEMENTS}

The authors thank the anonymous reviewers for useful comments that greatly enhanced the paper. The authors are responsible for any errors and omissions.

\section{REFERENCES}

Bhat CR (2003) Simulation estimation of mixed discrete choice models using randomized and scrambled Halton Sequences. Transport. Res. B 37(9): 837-855.

Bhat CR (2005) A multiple discrete-continuous extreme value model: formulation and application to discretionary time-use decisions. Transport. Res. B 39(8): 679-707.

Bhat CR (2008) The multiple discrete-continuous extreme value (MDCEV) model: role of utility function parameters, identification considerations, and model extensions. Transport. Res. B 42(3): 274-303

Bhat CR, Gossen R (2004) A mixed multinomial logit model analysis of weekend recreational episode type choice. Transport. Res. B 38(9): 767-787.

Carnegie Corporation of New York (1992) A matter of time: risk and opportunity in the nonschool hours. New York: Carnegie Corporation of New York.

Center for Disease Control (CDC) (2002) Youth risk behavior surveillance - United States, 2001. Morbidity and Mortality Weekly Report Surveillance Summaries, 51(SS-4), June 28.

Center for Disease Control (CDC) (2003) Physical activity levels among children aged 9-13 years - United States, 2002. Morbidity and Mortality Weekly Report, 52(33): 785-788.

Center for Disease Control (CDC) (2005) Positive Parenting Tips for Healthy Child Development. Child Development. Online at http://www.cdc.gov/ncbddd/child/documents/68YearOldsPositiveParenting.pdf 
Center for Disease Control (CDC) (2006) Youth risk behavior surveillance - United States, 2005. Morbidity and Mortality Weekly Report, Vol. 55, No. SS-5.

Clifton KJ (2003) Independent mobility among teenagers: an exploration of travel to after-school Activities. Transport. Res. Rec. 1854: 74-80.

Cole-Hamilton I, Harrop A, Street C (2002) The value of children's play and play provision: a systematic review of the literature. New Policy Institute. Available at: http://www.sportdevelopment.org.uk/playliterature2002.pdf. Accessed January 28, 2008.

Copperman RB, Bhat CR (2007a) An analysis of the determinants of children's weekend physical activity participation. Transportation 34(1): 67-87.

Copperman RB and Bhat CR (2007b) An exploratory analysis of children's daily time-use and activity patterns using the child development supplement (CDS) to the US panel study of income dynamics (PSID). Transport. Res. Rec. 2021: 36-44.

Darling N (2005) Participation in extracurricular activities and adolescent adjustment: crosssectional and longitudinal findings. J. of Youth and Adolescence 34(5): 493-505.

Eccles, J.S. (1999) The development of children ages 6 to 14. The Future of Children, 9(2): 3044.

Frusti T, Bhat CR, Axhausen KW (2003) An exploratory analysis of fixed commitments in individual activity-travel patterns. Transport. Res. Rec. 1807: 101-108.

Hofferth S, Brayfield A, Diech S, Holcomb P (1991) The national child care survey 1990. The Urban Press. Washington, DC.

Hofferth SL, Jankuniene J (2001) Life after school. Association for Supervision and Curriculum Development: 19-23.

Huebner AJ, Mancini JA (2003) Shaping structured out-of-school time use among youth: the effects of self, family, and friend systems. J. of Youth and Adolescence 32(6): 453-463.

Koolstra CM, van der Voort THA (1996) Longitudinal effects of television on children's leisuretime reading: a test of three explanatory models. Human Comm. Res. 23(1): 4-35.

Krizek K, Birnbaum A, Levinson D (2004) A schematic for focusing on youth in investigation of community design and physical activity. Am. J. of Health Promotion 19(1): 33-38.

Mackett RL, Lucas L, Paskins J, Turbin J (2005) The therapeutic value of children's everyday travel. Transport. Res. A 39: 205-219.

Mahoney JL, Stattin H (2000) Leisure activities and adolescent antisocial behavior: the role of structure and social context. J. of Adolescence 23: 113-117.

McDonald N (2006) An exploratory analysis of children's travel patterns. Transport. Res. Rec. 1997: $1-7$. 
McMillan TE (2007) The relative influence of urban form on a child's travel mode to school. Transport. Res. A 41: 69-79.

Osgood DW, Wilson JK, O'Malley PM, Bachman JG, Johnson LD (1996) Routine activities and individual deviant behavior. Am. Sociol. Rev. 61: 635-655.

Posner JK, Vandell DL (1994) Low-income children's after-school care: are there beneficial effects of after-school programs? Child Development 65(2) Children and Poverty: 440456.

Posner JK, Vandell DL (1997) After-school activities and the development of low-income urban children: a longitudinal study. Developmental Psychology 35(3): 868-879.

Reisner E (2003) Understanding family travel Demands as a critical component in work-family research, transportation and land-use. Presented at From 9 to 5 to 24/7: How Workplace Changes Impact Families, Work and Communities, Academic Work and Family Research Conference, March 2003.

Ross JG, Dotson CO, Gilbert GG, Katz SJ (1985) After physical Education- Physical Activity Outside of School Physical Education Programs. J. of Phys. Education Recreation, and Dance 56: 35-39.

Sallis JF, Prochaska JJ, Taylor WC (2000) A review of correlates of physical activity of children and adolescents. Med. and Sci. in Sports and Exercise 32(5): 963-975.

Sener IN, Bhat CR (2007) An analysis of the social context of children's weekend discretionary activity participation. Transportation 34(6): 697-721.

Shann MH (2001) Students' use of time outside of school: a case for after-school programs for urban middle school youth. The Urban Review 33(4): 339-355.

Stefan KJ, Hunt JD (2006) Age-based analysis of children in Calgary, Canada. Presented at the $85^{\text {th }}$ Annual Meeting of the Transportation Research Board, Washington, D.C., January.

Timmer SG, Eccles J, O'Brien K (1985) How children use time. In: Juster FT, Stafford FP (ed), Time, goods, and well-being. University of Michigan, Institute for Social Research, Ann Arbor: 353-381.

Transportation Research Board and Institute of Medicine (2005) Does the built environment influence physical activity? Examining the evidence. TRB Special Report 282, National Research Council, Washington, D.C.

United States Department of Health and Human Services (USDHHS) (2000) Healthy people 2010: understanding and improving health, 2nd edn. Washington, DC: U.S. Government Printing Office, November. 
Table 1. Aggregate Participation Rates in Leisure Activities

\begin{tabular}{|c|c|c|}
\hline \multirow{2}{*}{ Type of Leisure Activity } & \multicolumn{2}{|c|}{$\begin{array}{c}\text { Number and \% of } \\
\text { individuals participating }\end{array}$} \\
\cline { 2 - 3 } & Number & $\%$ \\
\hline Out-of-Home & 1660 & 91.7 \\
Weekday & 1073 & 59.3 \\
Weekend & 1511 & 83.5 \\
Both Days & 924 & 51.0 \\
\hline Physically Active & 1142 & 63.1 \\
In-home & 708 & 39.1 \\
Out-of-home & 720 & 39.8 \\
Weekday & 403 & 22.3 \\
Weekend & 502 & 27.7 \\
Both Days & 185 & 10.2 \\
In-home and Out-of-home & 286 & 15.8 \\
\hline Structured & 778 & 43.0 \\
In-home & 0 & 0.0 \\
Out-of-home & 778 & 43.0 \\
Weekday & 360 & 19.9 \\
Weekend & 598 & 33.0 \\
Both Days & 180 & 9.9 \\
\hline
\end{tabular}


Table 2. Descriptive Statistics of Leisure Activity Type Participation

\begin{tabular}{|c|c|c|c|c|c|}
\hline \multirow{2}{*}{$\begin{array}{l}\text { Activity } \\
\text { Type \# }\end{array}$} & \multirow{2}{*}{ Type of Leisure Activity } & \multirow{2}{*}{$\begin{array}{c}\text { Total } \\
\text { number } \\
(\%) \text { of } \\
\text { individuals } \\
\text { participating }\end{array}$} & \multirow{2}{*}{$\begin{array}{c}\text { Mean } \\
\text { duration of } \\
\text { participation } \\
\text { among those } \\
\text { participating } \\
\text { in the activity } \\
\text { (min.) }\end{array}$} & \multicolumn{2}{|c|}{$\begin{array}{l}\text { Number of individuals who } \\
\text { participate (\% of total number } \\
\text { participating) }\end{array}$} \\
\hline & & & & $\begin{array}{c}\text { Only in } \\
\text { activity type }\end{array}$ & $\begin{array}{l}\text { In the activity } \\
\text { type and other } \\
\text { activity types }\end{array}$ \\
\hline 1 & WE / IH / non-PHY / non-STR & $\begin{array}{c}1810 \\
(100 \%) \\
\end{array}$ & 338 & $\begin{array}{c}80 \\
(4 \%) \\
\end{array}$ & $\begin{array}{c}1730 \\
(96 \%)\end{array}$ \\
\hline 2 & WD / IH / non-PHY / non-STR & $\begin{array}{c}1810 \\
(100 \%) \\
\end{array}$ & 212 & $\begin{array}{c}80 \\
(4 \%) \\
\end{array}$ & $\begin{array}{c}1730 \\
(96 \%)\end{array}$ \\
\hline 3 & WE / IH / PHY / non-STR & $\begin{array}{c}521 \\
(29 \%)\end{array}$ & 98 & $\begin{array}{c}38 \\
(7 \%)\end{array}$ & $\begin{array}{c}483 \\
(93 \%)\end{array}$ \\
\hline 4 & WD / IH / PHY / non-STR & $\begin{array}{c}385 \\
(21 \%)\end{array}$ & 63 & $\begin{array}{c}9 \\
(2 \%)\end{array}$ & $\begin{array}{c}376 \\
(98 \%)\end{array}$ \\
\hline 5 & WE / OH / non-PHY / non-STR & $\begin{array}{c}1242 \\
(69 \%)\end{array}$ & 190 & $\begin{array}{c}167 \\
(13 \%)\end{array}$ & $\begin{array}{c}1075 \\
(87 \%)\end{array}$ \\
\hline 6 & WD / OH / non-PHY / non-STR & $\begin{array}{c}756 \\
(42 \%)\end{array}$ & 100 & $\begin{array}{c}47 \\
(6 \%) \\
\end{array}$ & $\begin{array}{c}709 \\
(94 \%)\end{array}$ \\
\hline 7 & WE / OH / PHY / non-STR & $\begin{array}{c}410 \\
(23 \%)\end{array}$ & 128 & $\begin{array}{c}16 \\
(4 \%)\end{array}$ & $\begin{array}{c}394 \\
(96 \%)\end{array}$ \\
\hline 8 & WD / OH / PHY / non-STR & $\begin{array}{c}251 \\
(14 \%)\end{array}$ & 85 & $\begin{array}{c}4 \\
(2 \%) \\
\end{array}$ & $\begin{array}{c}247 \\
(98 \%)\end{array}$ \\
\hline 9 & WE / OH / non-PHY / STR & $\begin{array}{c}525 \\
(29 \%)\end{array}$ & 171 & $\begin{array}{c}34 \\
(7 \%) \\
\end{array}$ & $\begin{array}{c}491 \\
(93 \%)\end{array}$ \\
\hline 10 & WD / OH / non-PHY / STR & $\begin{array}{c}217 \\
(12 \%) \\
\end{array}$ & 109 & $\begin{array}{c}4 \\
(2 \%)\end{array}$ & $\begin{array}{c}213 \\
(98 \%) \\
\end{array}$ \\
\hline 11 & WE / OH / PHY / STR & $\begin{array}{c}107 \\
(6 \%)\end{array}$ & 138 & $\begin{array}{c}3 \\
(3 \%)\end{array}$ & $\begin{array}{c}104 \\
(97 \%)\end{array}$ \\
\hline 12 & WD / OH / PHY / STR & $\begin{array}{c}163 \\
(9 \%)\end{array}$ & 111 & $\begin{array}{c}4 \\
(3 \%)\end{array}$ & $\begin{array}{c}159 \\
(97 \%)\end{array}$ \\
\hline
\end{tabular}

Note: The last 10 rows of the column indicates the number of individuals (\% of total number participating) who participate only in the activity type in addition to the in-home, non-physical, non-structured activity type that is always consumed. Thus, $38(7 \%)$ children out of 521 participate only in WE/IH/PHY/non-STR activity in addition to the always consumed IH/non-PHY/non-STR activities, while the rest $483(93 \%)$ participate in multiple activity categories among those in the last 10 rows as well as in in-home, non-physical, non-structured activities. 
Table 3. Mixed MDCEV Model Results

\begin{tabular}{|c|c|c|c|c|c|c|c|c|c|c|c|c|}
\hline \multirow{3}{*}{$\begin{array}{c}\text { Child } \\
\text { Demographics }\end{array}$} & \multicolumn{4}{|c|}{$\begin{array}{c}\text { Child age } \\
\text { Base "Aged 12-15" }\end{array}$} & \multirow{2}{*}{\multicolumn{2}{|c|}{ Male }} & \multicolumn{4}{|c|}{ Child's Race } & \multirow{2}{*}{\multicolumn{2}{|c|}{$\begin{array}{l}\text { Physically } \\
\text { challenged }\end{array}$}} \\
\hline & \multicolumn{2}{|c|}{ Aged 5-7 } & \multicolumn{2}{|c|}{ Aged 8-11 } & & & \multicolumn{2}{|c|}{$\begin{array}{l}\text { Caucasian- } \\
\text { American }\end{array}$} & \multicolumn{2}{|c|}{ Hispanic } & & \\
\hline & Est. & t-stat & Est. & t-stat & Est. & t-stat & Est. & t-stat & Est. & t-stat & Est. & t-stat \\
\hline \begin{tabular}{l}
\multicolumn{2}{c}{ Activity Dimension } \\
Activity day \\
Weekday (WD)
\end{tabular} & -0.26 & -4.06 & -0.25 & -4.62 & - & - & - & - & - & - & - & - \\
\hline $\begin{array}{l}\text { Activity location } \\
\text { Out-of-home }(\mathrm{OH})\end{array}$ & -0.21 & -2.56 & -0.22 & -3.27 & -0.18 & -3.07 & - & - & 0.13 & 1.07 & -0.40 & -2.64 \\
\hline $\begin{array}{l}\text { Activity type } 1 \\
\text { Physically active (PHY) }\end{array}$ & 0.14 & 1.61 & 0.24 & 3.28 & 0.28 & 4.53 & 0.40 & 5.20 & 0.25 & 2.02 & -0.22 & -1.34 \\
\hline $\begin{array}{l}\text { Activity type } 2 \\
\text { Structured (STR) }\end{array}$ & -0.65 & -1.40 & - & - & - & - & - & - & - & - & - & - \\
\hline $\begin{array}{l}\quad \underline{\text { Interactions }} \\
\mathrm{OH} / \mathrm{PHY} \\
\mathrm{OH} / \mathrm{PHY} / \mathrm{STR} \\
\text { WD / OH / STR } \\
\mathrm{OH} / \mathrm{non}-\mathrm{PHY} \text { / non-STR } \\
\text { WD / OH / non-PHY / STR } \\
\text { WE / OH / PHY / non-STR }\end{array}$ & $\begin{array}{c}- \\
- \\
-0.65 \\
- \\
- \\
-0.30\end{array}$ & $\begin{array}{c}- \\
- \\
-3.63 \\
- \\
- \\
-2.13\end{array}$ & $\begin{array}{l}- \\
- \\
- \\
- \\
- \\
-\end{array}$ & $\begin{array}{l}- \\
- \\
- \\
- \\
- \\
-\end{array}$ & $\begin{array}{c}- \\
- \\
- \\
- \\
-0.28 \\
-\end{array}$ & $\begin{array}{c}- \\
- \\
- \\
- \\
-1.92 \\
-\end{array}$ & $\begin{array}{l}- \\
- \\
0.28 \\
- \\
- \\
-\end{array}$ & $\begin{array}{c}- \\
- \\
2.22 \\
- \\
- \\
-\end{array}$ & $\begin{array}{l}- \\
- \\
- \\
- \\
- \\
-\end{array}$ & $\begin{array}{l}- \\
- \\
- \\
- \\
- \\
-\end{array}$ & $\begin{array}{l}- \\
- \\
- \\
- \\
- \\
-\end{array}$ & $\begin{array}{l}- \\
- \\
- \\
- \\
- \\
-\end{array}$ \\
\hline
\end{tabular}


Table 3. (continued) Mixed MDCEV Model Results

\begin{tabular}{|c|c|c|c|c|c|c|c|c|c|c|c|c|}
\hline \multirow{3}{*}{$\begin{array}{c}\text { Parent } \\
\text { Demographics }\end{array}$} & \multicolumn{4}{|c|}{$\begin{array}{c}\text { Education-related } \\
\text { Variables }\end{array}$} & \multicolumn{4}{|c|}{$\begin{array}{l}\text { Employment } \\
\text { Variables }\end{array}$} & \multicolumn{4}{|c|}{ Physical Activity Participation } \\
\hline & \multicolumn{2}{|c|}{$\begin{array}{c}\text { Mother } \\
\text { Bachelor's or more }\end{array}$} & \multicolumn{2}{|c|}{$\begin{array}{c}\text { Father } \\
\text { Bachelor's or more }\end{array}$} & \multicolumn{2}{|c|}{$\begin{array}{l}\text { Mother } \\
\text { Employed }\end{array}$} & \multicolumn{2}{|c|}{$\begin{array}{l}\text { Father } \\
\text { Employed }\end{array}$} & \multicolumn{2}{|c|}{$\begin{array}{l}\text { Mother } \\
\text { Physically Active } \\
\text { or more }\end{array}$} & \multicolumn{2}{|c|}{$\begin{array}{c}\text { Father } \\
\text { Physically Active } \\
\text { or more }\end{array}$} \\
\hline & Est. & t-stat & Est. & t-stat & Est. & t-stat & Est. & t-stat & Est. & t-stat & Est. & t-stat \\
\hline $\begin{array}{l}\text { Activity Dimension } \\
\text { Activity day } \\
\text { Weekday (WD) }\end{array}$ & - & - & - & - & - & - & - & - & - & - & - & - \\
\hline $\begin{array}{l}\text { Activity location } \\
\text { Out-of-home }(\mathrm{OH})\end{array}$ & 0.17 & 2.67 & - & - & 0.13 & 2.09 & 0.13 & 1.10 & - & - & - & - \\
\hline $\begin{array}{l}\text { Activity type } 1 \\
\text { Physically active (PHY) }\end{array}$ & - & - & - & - & - & - & - & - & 0.20 & 1.88 & 0.13 & 1.68 \\
\hline $\begin{array}{l}\text { Activity type } 2 \\
\text { Structured (STR) }\end{array}$ & 0.28 & 2.89 & 0.43 & 4.42 & - & - & - & - & - & - & - & - \\
\hline $\begin{array}{l}\quad \text { Interactions } \\
\mathrm{OH} / \mathrm{PHY} \\
\mathrm{OH} / \mathrm{PHY} / \mathrm{STR} \\
\text { WD / OH / STR } \\
\mathrm{OH} / \text { non-PHY / non-STR } \\
\text { WD / OH / non-PHY / STR } \\
\text { WE / OH / PHY / non-STR }\end{array}$ & $\begin{array}{l}- \\
- \\
- \\
- \\
- \\
-\end{array}$ & $\begin{array}{l}- \\
- \\
- \\
- \\
- \\
-\end{array}$ & $\begin{array}{l}- \\
- \\
- \\
- \\
- \\
-\end{array}$ & $\begin{array}{l}- \\
- \\
- \\
- \\
- \\
-\end{array}$ & $\begin{array}{l}- \\
- \\
- \\
- \\
- \\
-\end{array}$ & $\begin{array}{l}- \\
- \\
- \\
- \\
- \\
-\end{array}$ & $\begin{array}{l}- \\
- \\
- \\
- \\
- \\
-\end{array}$ & $\begin{array}{l}- \\
- \\
- \\
- \\
- \\
-\end{array}$ & $\begin{array}{l}- \\
- \\
- \\
- \\
- \\
-\end{array}$ & $\begin{array}{l}- \\
- \\
- \\
- \\
- \\
-\end{array}$ & $\begin{array}{l}- \\
- \\
- \\
- \\
- \\
-\end{array}$ & $\begin{array}{l}- \\
- \\
- \\
- \\
- \\
-\end{array}$ \\
\hline
\end{tabular}


Table 3. (continued) Mixed MDCEV Model Results

\begin{tabular}{|c|c|c|c|c|c|c|c|c|c|c|}
\hline \multirow{3}{*}{$\begin{array}{c}\text { Household } \\
\text { Demographics }\end{array}$} & \multirow{2}{*}{\multicolumn{2}{|c|}{$\begin{array}{c}\text { \# of } \\
\text { Children }\end{array}$}} & \multirow{2}{*}{\multicolumn{2}{|c|}{$\begin{array}{l}\text { Single Parent } \\
\text { Family }\end{array}$}} & \multirow{2}{*}{\multicolumn{2}{|c|}{$\begin{array}{c}\text { Low } \\
\text { Income } \\
\text { (<25K) } \\
\end{array}$}} & \multirow{2}{*}{\multicolumn{2}{|c|}{$\begin{array}{c}\text { \# of } \\
\text { Vehicles }\end{array}$}} & \multirow{2}{*}{\multicolumn{2}{|c|}{$\begin{array}{l}\text { Housing Type } \\
\text { Apartment Unit }\end{array}$}} \\
\hline & & & & & & & & & & \\
\hline & Est. & t-stat & Est. & t-stat & Est. & t-stat & Est. & t-stat & Est. & t-stat \\
\hline $\begin{array}{l}\text { Activity Dimension } \\
\text { Activity day }\end{array}$ & & & & & & & & & & \\
\hline Weekday (WD) & - & - & - & - & - & - & - & - & - & - \\
\hline $\begin{array}{l}\text { Activity location } \\
\text { Out-of-home (OH) }\end{array}$ & -0.11 & -3.36 & 0.26 & 2.04 & -0.11 & -1.19 & 0.05 & 1.08 & 0.15 & 1.65 \\
\hline $\begin{array}{l}\text { Activity type } 1 \\
\text { Physically active (PHY) }\end{array}$ & 0.07 & 2.16 & - & - & - & - & -0.11 & -2.78 & - & - \\
\hline $\begin{array}{l}\text { Activity type } 2 \\
\text { Structured (STR) }\end{array}$ & 0.14 & 2.85 & - & - & -0.35 & -2.50 & - & - & - & - \\
\hline Interactions & & & & & & & & & & \\
\hline $\mathrm{OH} / \mathrm{PHY}$ & - & - & - & - & - & - & - & - & - & - \\
\hline $\mathrm{OH} / \mathrm{PHY} / \mathrm{STR}$ & -0.19 & -2.21 & - & - & - & - & & & - & - \\
\hline WD / OH / STR & - & - & - & - & -0.37 & -1.78 & - & - & - & - \\
\hline $\mathrm{OH} /$ non-PHY / non-STR & - & - & - & - & - & - & 0.05 & 1.20 & - & - \\
\hline WD / OH / non-PHY / STR & - & - & - & - & - & - & - & - & - & - \\
\hline WE / OH / PHY / non-STR & - & - & - & - & - & - & - & - & - & - \\
\hline
\end{tabular}


Table 3. (continued) Mixed MDCEV Model Results

\begin{tabular}{|c|c|c|c|c|c|c|c|c|c|c|}
\hline \multirow{3}{*}{$\begin{array}{c}\text { Household Location } \\
\text { Variables } \\
\text { and } \\
\text { Seasonal Effects }\end{array}$} & \multirow{2}{*}{\multicolumn{2}{|c|}{$\begin{array}{c}\begin{array}{c}\text { Zonal Location } \\
\text { Variables }\end{array} \\
\text { Rural } \\
\end{array}$}} & \multicolumn{4}{|c|}{$\begin{array}{l}\text { Regional Location } \\
\text { Variables }\end{array}$} & \multicolumn{4}{|c|}{ Seasonal Effects } \\
\hline & & & \multicolumn{2}{|c|}{ Northeast } & \multicolumn{2}{|c|}{ Northcentral } & \multicolumn{2}{|c|}{ Fall } & \multicolumn{2}{|c|}{ Winter } \\
\hline & Est. & t-stat & Est. & t-stat & Est. & t-stat & Est. & t-stat & Est. & t-stat \\
\hline $\begin{array}{l}\text { Activity Dimension } \\
\text { Activity day } \\
\text { Weekday }\end{array}$ & - & - & - & - & - & - & - & - & - & - \\
\hline $\begin{array}{l}\text { Activity location } \\
\text { Out-of-home }\end{array}$ & -0.27 & -1.42 & -0.13 & -1.50 & - & - & - & - & -0.09 & -1.37 \\
\hline $\begin{array}{l}\text { Activity type } 1 \\
\text { Physical }\end{array}$ & 0.26 & 1.36 & -0.43 & -4.35 & -0.46 & -5.72 & - & - & - & - \\
\hline $\begin{array}{l}\text { Activity type } 2 \\
\text { Structured }\end{array}$ & 0.84 & 3.42 & - & - & - & - & - & - & -0.10 & -1.15 \\
\hline $\begin{array}{l}\quad \underline{\text { Interactions }} \\
\text { OH / PHY } \\
\text { OH / PHY / STR } \\
\text { WD / OH / STR } \\
\text { OH / non-PHY / non-STR } \\
\text { WD / OH / non-PHY / STR } \\
\text { WE / OH / PHY / non-STR }\end{array}$ & $\begin{array}{l}- \\
- \\
- \\
- \\
- \\
-\end{array}$ & $\begin{array}{l}- \\
- \\
- \\
- \\
-\end{array}$ & $\begin{array}{l}- \\
- \\
- \\
- \\
- \\
-\end{array}$ & $\begin{array}{l}- \\
- \\
- \\
- \\
- \\
-\end{array}$ & $\begin{array}{l}- \\
- \\
- \\
- \\
- \\
-\end{array}$ & $\begin{array}{l}- \\
- \\
- \\
- \\
- \\
-\end{array}$ & $\begin{array}{c}-0.34 \\
- \\
- \\
- \\
- \\
-\end{array}$ & $\begin{array}{c}-2.63 \\
- \\
- \\
- \\
- \\
-\end{array}$ & $\begin{array}{c}-0.24 \\
- \\
- \\
- \\
- \\
-\end{array}$ & $\begin{array}{c}-2.00 \\
- \\
- \\
- \\
- \\
-\end{array}$ \\
\hline
\end{tabular}


Table 3. (continued) Mixed MDCEV Model Results

\begin{tabular}{|c|c|c|c|}
\hline \multirow[b]{2}{*}{ Activity Type \# } & \multirow[b]{2}{*}{ Type of Leisure Activity } & \multicolumn{2}{|c|}{ Baseline Preference Constants } \\
\hline & & Estimate & t-statistic \\
\hline $\begin{array}{l}1 \\
2\end{array}$ & $\begin{array}{l}\text { WE / IH / non-PHY / non-STR } \\
\text { WD / IH / non-PHY / non-STR }\end{array}$ & $\begin{array}{c}- \\
-0.25\end{array}$ & $\begin{array}{c}- \\
-5.06\end{array}$ \\
\hline $\begin{array}{c}3 \\
4 \\
5 \\
6 \\
7 \\
8 \\
9 \\
10 \\
11 \\
12\end{array}$ & $\begin{array}{l}\text { WE / IH / PHY / non-STR } \\
\text { WD / IH / PHY / non-STR } \\
\text { WE / OH / non-PHY / non-STR } \\
\text { WD / OH / non-PHY / non-STR } \\
\text { WE / OH / PHY / non-STR } \\
\text { WD / OH / PHY / non-STR } \\
\text { WE / OH / non-PHY / STR } \\
\text { WD / OH / non-PHY / STR } \\
\text { WE / OH / PHY / STR } \\
\text { WD / OH / PHY / STR }\end{array}$ & $\begin{array}{l}-2.53 \\
-2.73 \\
-0.53 \\
-1.18 \\
-2.38 \\
-2.85 \\
-2.40 \\
-3.20 \\
-4.22 \\
-3.58\end{array}$ & $\begin{array}{l}-15.94 \\
-16.63 \\
-2.75 \\
-5.98 \\
-9.20 \\
-10.83 \\
-10.13 \\
-12.20 \\
-13.15 \\
-11.00\end{array}$ \\
\hline
\end{tabular}

Note: Weekend, in-home, non-physical, non-structured (WE / IH / non-PHY / non-STR) leisure activity is the base category for the baseline preference constants

Table 4. Satiation Parameters - $\gamma$

\begin{tabular}{||c||c||c||c||}
\hline Activity Type \# & Type of Leisure Activity & Parameter $(\gamma)$ & t-statistic \\
\hline \hline 1 & WE / IH / non-PHY / non-STR & - & - \\
2 & WD / IH / non-PHY / non-STR & - & - \\
3 & WE / IH / PHY / non-STR & 0.57 & 13.53 \\
4 & WD / IH / PHY / non-STR & 0.39 & 12.09 \\
5 & WE / OH / non-PHY / non-STR & 0.78 & 18.02 \\
6 & WD / OH / non-PHY / non-STR & 0.48 & 16.13 \\
7 & WE / OH / PHY / non-STR & 0.95 & 11.96 \\
8 & WD / OH / PHY / non-STR & 0.63 & 9.78 \\
9 & WE / OH / non-PHY / STR & 1.36 & 12.72 \\
10 & WD / OH / non-PHY / STR & 0.98 & 8.99 \\
11 & WE / OH / PHY / STR & 1.42 & 6.18 \\
12 & WD / OH / PHY / STR & 1.10 & 7.92 \\
\hline
\end{tabular}

Note: $t$-statistic is computed for the test that the satiation parameter $\gamma$ is equal to 0 